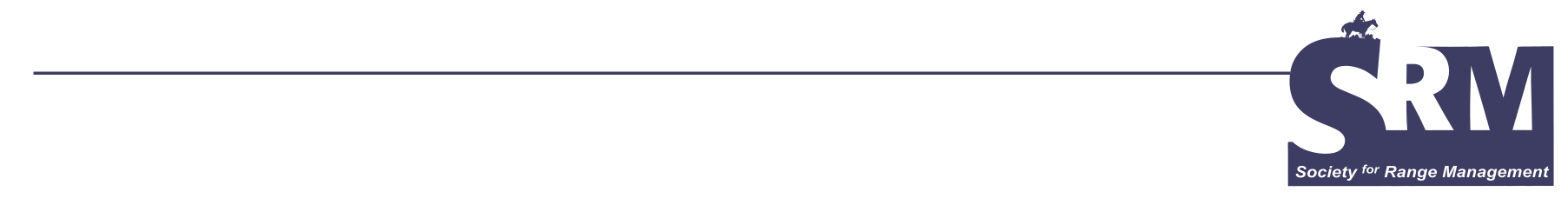

\title{
Water Management in Northwestern Egypt
}

\section{By Gary Frasier}

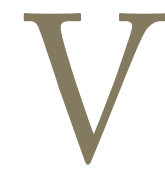

isualize an area of $50 \mathrm{~km}$ by $400 \mathrm{~km}(30 \times 120$ miles) supporting an agricultural community of 40,000 people. Farmers raise sheep and goats, and better soil areas are planted to trees (figs and olive; Photo 1).

Now, impose a climate of a desert regime with 100-200 $\mathrm{mm}$ (4-8 inches) of precipitation a year, mostly arriving during the winter months (November-March). This is the area along the Mediterranean coast of northwestern Egypt, from west of Alexandria to the Libyan border and extending inland for 50-70 km (30-40 miles).

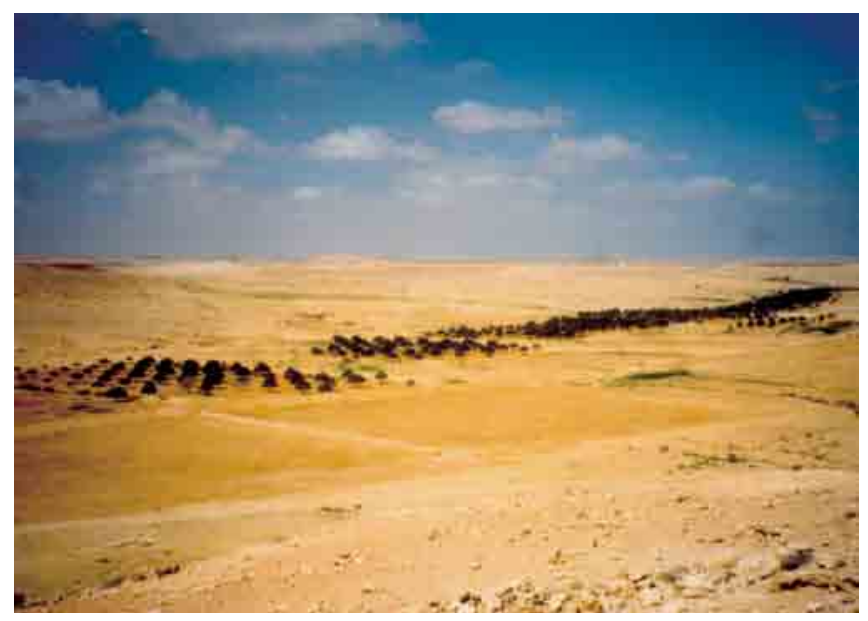

Photo 1. Wadi in northwestern Egypt with fig and olive trees.

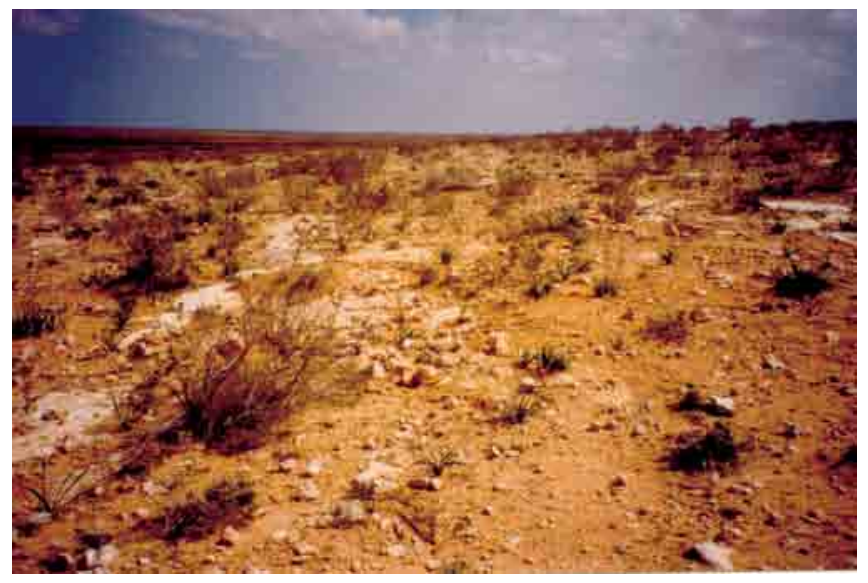

Photo 2. Native vegetation on upland areas.

Historically, the land was pastoral desert rangelands, grazed by nomadic Bedouins moving their animals in an ever-changing pattern. Since World War II, the Bedouins have been furnished houses and now reside in one place. The animals graze the same general areas around the settlements yearlong. This has resulted in severe overgrazing of the limited native forage resource. Many areas have been disturbed by rock-mining activities. The ground is ripped by bulldozers to dislodge rocks that are hand picked and used for various construction projects: crushed for gravel, rock fences, and houses (Photo 2). 


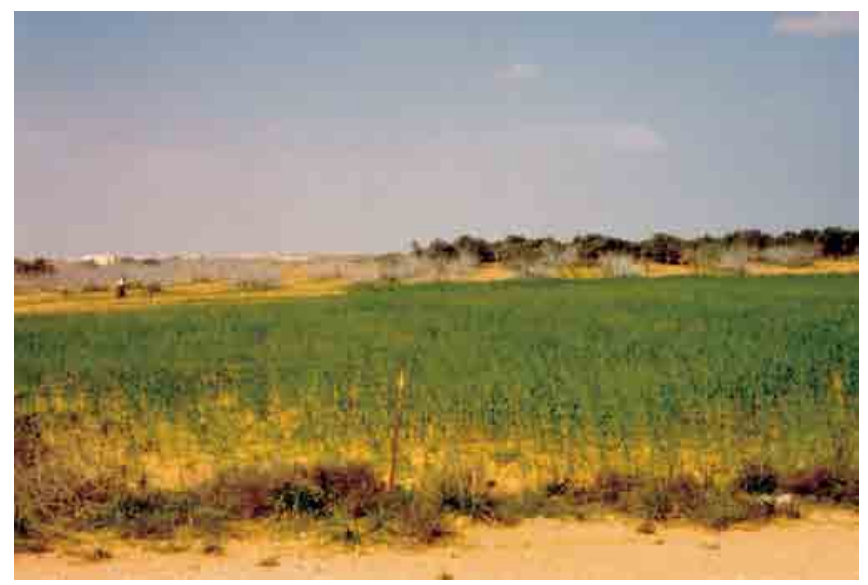

Photo 3. Dryland barley.

A considerable amount of the land (traditional rangeland) is planted each year to a dryland barley. The precipitation patterns and quantity are marginal for the barley to produce a grain crop (about 2 years in 10). In about 6 years in 10, there is sufficient rain to produce barley fodder (Photo 3 ).

There is essentially no water in the area except for what falls as precipitation. Drinking and household water for most of the Bedouin homes is obtained by a process called water harvesting. Water harvesting is simply the process of collecting precipitation runoff water from an area and storing it until needed. A typical system for 2-4 families would have a small area (4-6 acres) for water collecting. The collected water is stored in underground cisterns. Other types of water harvesting and runoff farming installations (ie, microcatchments and strip-runoff farming) are used to maximize the limited water falling as rain.

In March 1997, I visited a site along the northwest coast under the sponsorship of the International Center for Agriculture Research in the Dry Areas (ICARDA) headquartered in Aleppo, Syria. The project involved the integrated management of agriculture, including water harvesting, as a means of improving production of range vegetation, grain crops, and fruit trees.

\section{Major Systems of Water Harvesting and Water Management \\ The Wadi-Bed System}

These systems may be more appropriately termed as floodwater management systems. They consist of a series of dykes constructed across the wadi (ephemeral channel) to retard (pond) the runoff water coming down channel. It is believed the ponded water would drop any sediment and provide a more fertile seedbed. As the ponded water fills the dyke, excess water flows around the end or over the spillway to the next area (Fig. 1). The area between dykes is usually $1-5$ ha (2.5-12 acres) in size (estimate) usually planted to trees (figs, olive). At the upper end of the wadi (headwater), the areas are frequently planted to barley. The vast rangelands

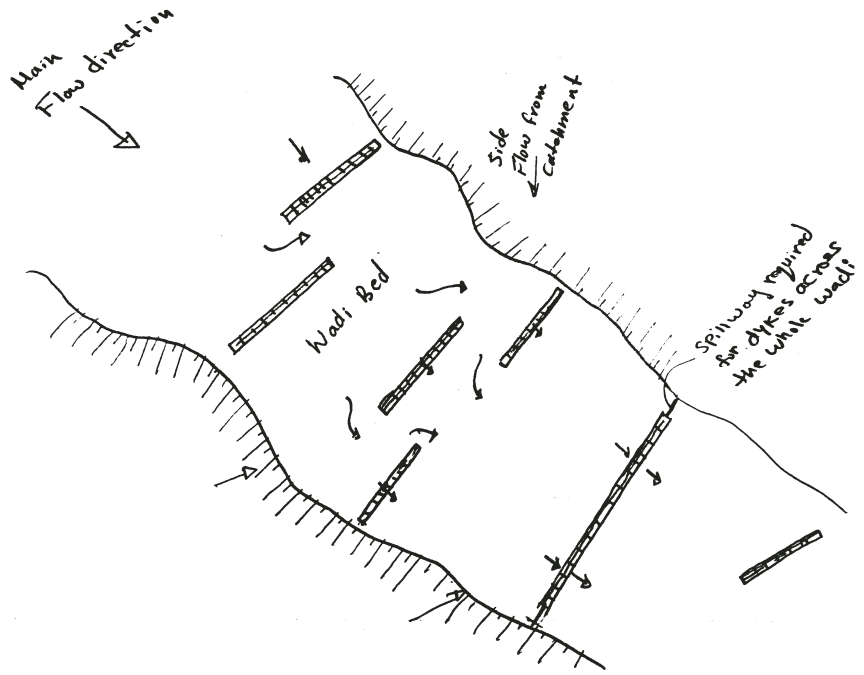

Figure 1a. Schematic of stone dykes to maximize infiltration of water into wadi channels.

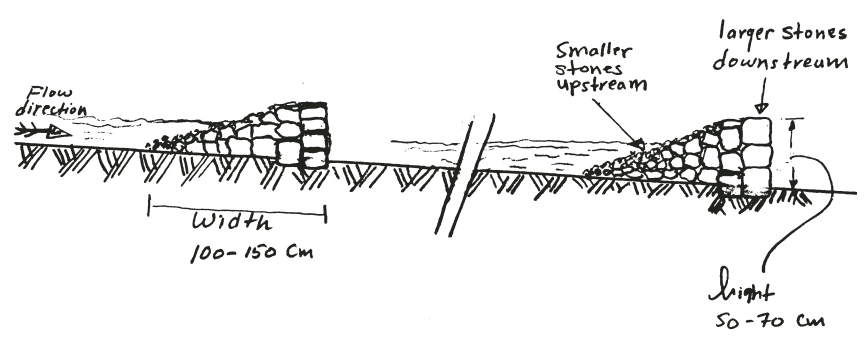

Figure 1b. Insert shows the recommended shape of the dykes.

upstream and along the edges of the wadi provide the water collection area (Photo 4).

Dykes are frequently constructed of hand-laid rock walls approximately $1 \mathrm{~m}$ (3 feet) wide and $1 \mathrm{~m}$ (3 feet) high (estimate). In some dykes the rocks are cemented in place. Most dykes do not fully cross the wadi (Photo 5). Larger dykes frequently have a constructed spillway to pass major flows, sometimes in the middle and other times at one end. The spillways are usually and estimated $0.5 \mathrm{~m}$ (1.5 feet) lower than the top of the dyke (Photo 6). In many wadi systems, only 2-3 flows per year pass through the systems. The stone with mortar walls (called mabani) stop both water and sediments totally. With time, the mabani will be filled with eroded soil, and the wadi bed-slope will eventually be modified. In the meantime, lots of deep percolation of the ponded water occurs.

\section{Cisterns}

The cistern systems consist of a water collection area 1-2 ha (2.5 acres) in size (estimated), which has, at the lower corner, an excavated below-ground water storage chamber (Photo 7). A continuous layer of rock prevails in the region at a depth of 50 to $100 \mathrm{~cm}$ below the ground surface, which forms the ceil- 


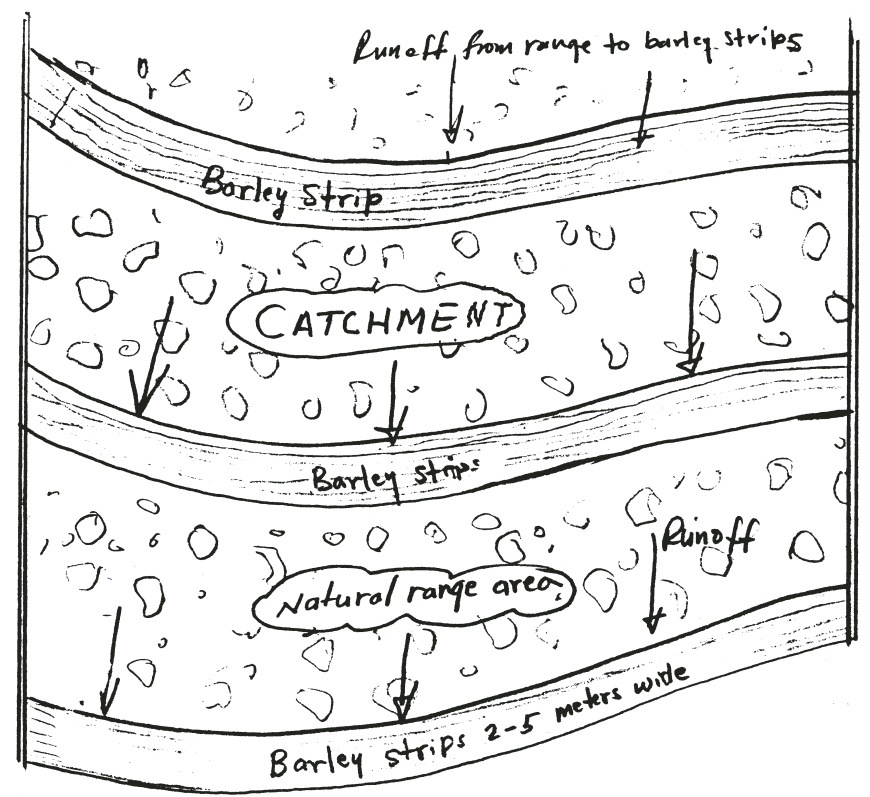

Figure 2. Schematic of barley grown in strips using runoff from undisturbed range areas.

ing of the chamber. This chamber is lined with plaster to prevent seepage of the collected water. There are usually small earthen berms at the lower edge of the catchment area to direct the water into the storage cistern. Cistern sizes range between 200 and $300 \mathrm{~m}^{3}$ (5,000-8,000 gallons). In many areas, cisterns are the primary water source for domestic (drinking, washing, cooking, etc) and animal use. Water may also be applied by hand to plants (gardens, trees, etc).

\section{Depression Systems-Strip Farming}

These systems are usually on the upland sites, out of the major wadi drainages. Areas are selected that have some natural water runoff from higher slopes that pass over the area. They frequently have a small rock or earthen ridge around the lower sides. The planting area is chiseled and seeded to barley (Fig. 2). There is very little seedbed preparation and

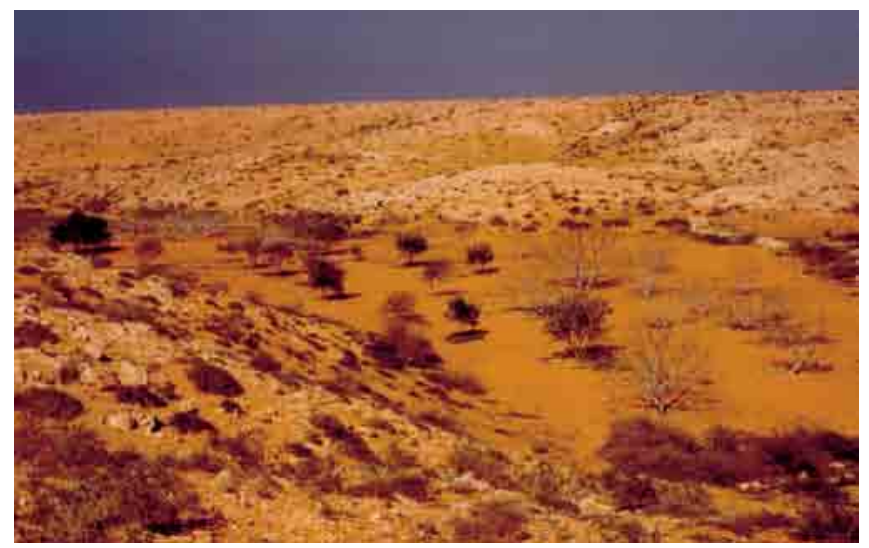

Photo 4. Drainage area to a typical wadi.

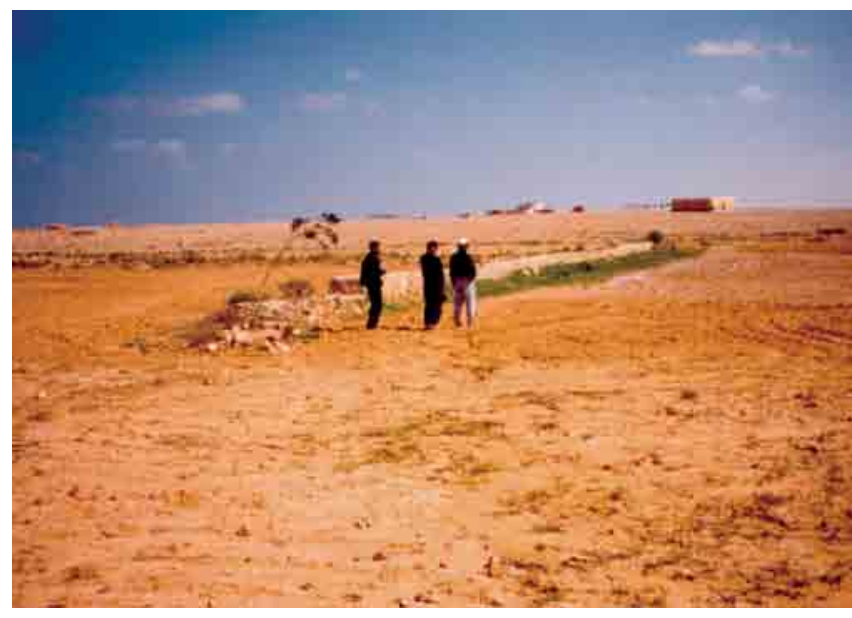

Photo 5. Stone dyke across the middle of a wadi.

no collection area surface modification. Signs of severe water stress were observed in several areas. Soils are only 1-meter (3-feet) deep, and there has been a drought for 2 consecutive years. Range shrubs are being removed to plant barley and watermelon. Wind erosion is obvious, and sand dunes are being formed.

\section{The Earth Bund Systems}

Earth bunds are formed on lands above and within the wadi bed to collect water from local, usually small, catchments. The bunds are similar to the so-called tabia in Tunisia. Several basins are sometimes connected to each other and to the catchment in a system similar to the saylada system in Baluchistan. Improper spillways and drop structures are common and can cause the collapse of the system.

\section{Microcatchments}

The microcatchment water-harvesting basins are being evaluated at a research site of ICARDA. They consist of small water-collection areas that drain into a central area in a corner where a single tree is planted. The areas are enclosed with small earthen berms to direct the runoff water to the planted area. The collected water infiltrates into the soil around the tree. Each tree has its own runoff-water contributing area (Fig. 3). Studies are also evaluating the potential of using several small trees or shrubs at the lower side of the water collection area (Photo 8). Recent rains caused substantial runoff from the basins to the trees, which greatly increased the farmers' confidence in the system.

\section{General Observations}

1. The area is crowded with both reports and activities on water harvesting. This has been going on for a long time. Several projects are concentrating on the wadi-bed floodwater and the cistern systems. Most of these projects are concerned with development. Farmers generally are happy with the water-harvesting developments. Several successful intervention projects are present in several areas with 


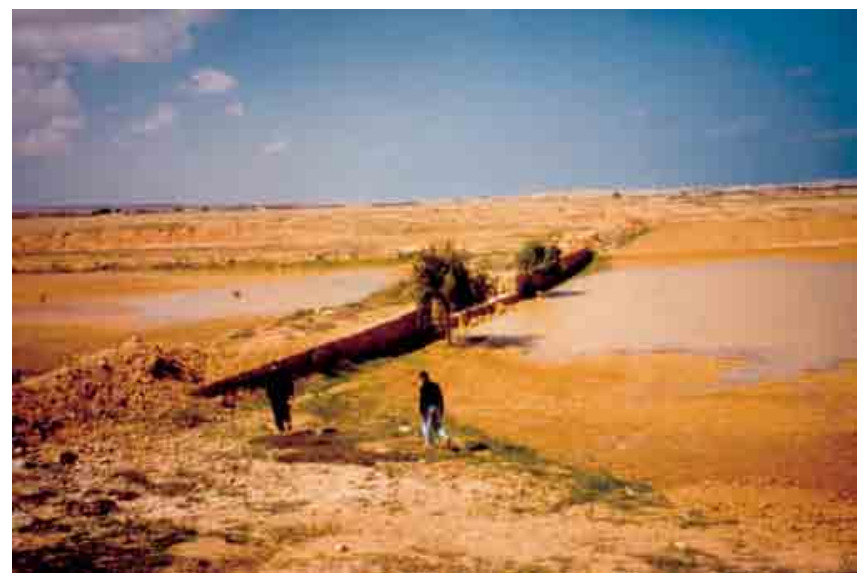

Photo 6. Stone dyke with a spillway across the entire wadi.

obvious heavy investment for small acreages. Many projects do not look economical nor something that can be adopted by farmers. Most of the costs are covered by the project, but the farmers primarily contribute the labor.

2. It is obvious that farmers are mismanaging many range areas by cultivating for barley and watermelon, which involves removing the shrubs that are stabilizing the soils. This is resulting in severe wind erosion with sand dunes forming in several areas.

3. Although major development work is going on, there was no evidence of measuring or estimating the quantity of runoff water in the wadi or outside. No estimate can be made about the water balance, the flow of the water, the deep percolation, the moisture use throughout the growing season, rainfall intensity, or rainfall runoff coefficients, all of which are important factors in designing these structures and ensuring fair distribution of water throughout the area.

4. Work in the wadi beds upstream and downstream does not seem to be coordinated. Many activities upstream are negatively affecting old water beneficiaries downstream. In some areas, fruit trees near the coast at the outlet of a long wadi are showing signs of stress from inadequate water. A farmer indicated his anger at the use of solid walls across the wadi (mabani) because the walls stop water from continuing downstream, and none is now available. It is obvious that much of the water in the wadi bed system is being collected upstream. This will be a greater factor when the ongoing works are completed. The system is unbalanced for effective and equitable water use among upstream and downstream landowners.

5. Systems are being developed without looking into what happens to other functions in the area. For example, improving rangelands by water harvesting is an objective of the project. However, any improvement in retaining the water on the rangeland will reduce the runoff to the wadies. At the same time, wadies are being developed to receive more water. These two concepts are incompatible, and a compromise has to be achieved somewhere. Because

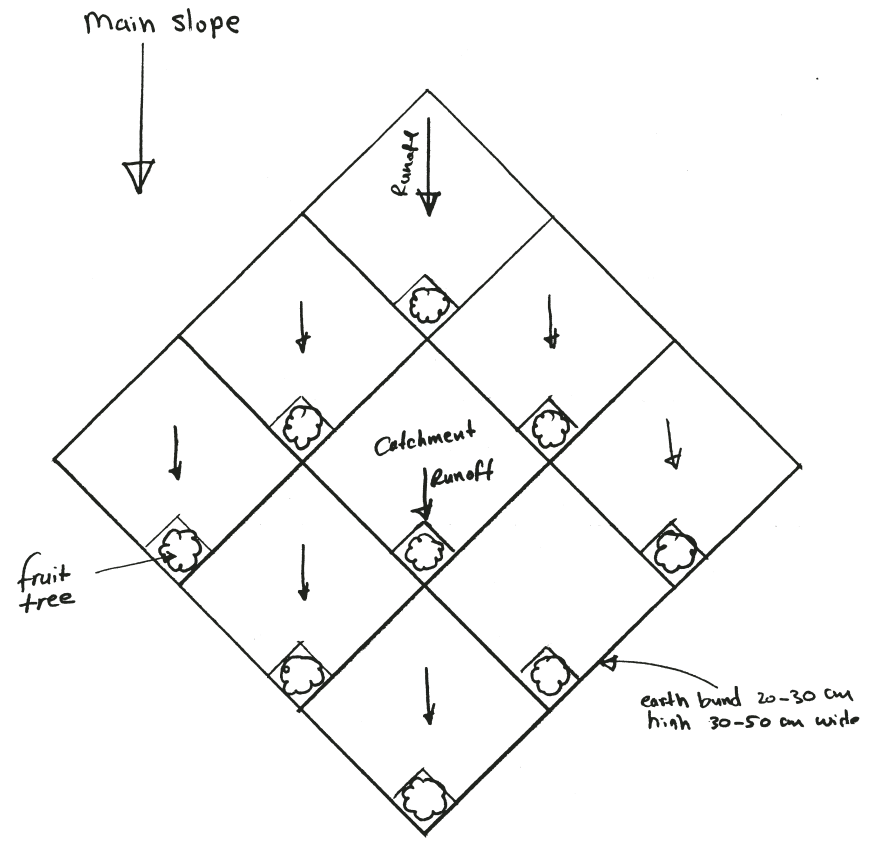

Figure 3. Layout of a typical group of microcatchments for growing trees.

the existing upland rangeland catchments now supplying water for the wadi bed system are more fully developed for retaining water on-site, the wadi systems will become ineffective and/or disappear. As a catchment is developed for barley or for rangeland, it becomes a user for water rather than a water catchment for downstream areas. An overall strategy based on the whole system (rangeland and cultivated areas) is required if the system (the entire watershed) is to function properly in the future.

6. Water is lost from the wadi bed system as deep percolation occurs behind the solid stone-mortar walls (mabani). This is due to the total blockage of the flow when the spillway is high.

\section{Recommendations}

1. The stone dykes being built in wadi beds are rectangular and sometimes very high, so they close the entire wadi bed. Collapse of these dykes can happen easily, and their function may not be accomplished. An alternative to the rectangular stone dykes is the triangular shape (Fig. 1b). If the dykes were built to heights not exceeding $60-70 \mathrm{~cm}$, the stability of the dykes would improve and would trap sediments. The dykes could also be designed to be located only in the lower point of the bed, not continuously across the wadi (Fig. 1). Also, on the solid dykes (mabani) across the wadies, the spillways are usually very high, and the dams hold lots of water for a long time, which can be lost in deep percolation, depriving downstream farmers of the water. Low spillways could be constructed initially to allow most of the water to pass. Later, when the basin is filled with sediments, the spillway crest could be heightened to 


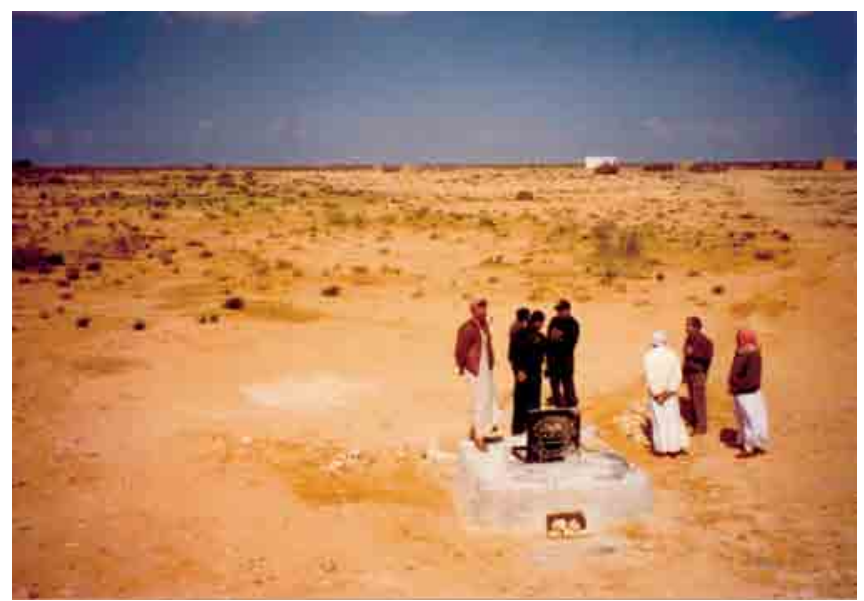

Photo 7. Top of a cistern for storing water from the water-collection area in background.

store only that water needed by the farmer. This could be continued until the entire slope behind the wall is filled with sediments.

2. It would be worthwhile to test the runoff-strip method for growing barley alternatively with rangeland (Fig. 2). The rangeland areas provide the needed water to improve the success of the barley crop. At the same time, the farmers have critical rangeland for their animals. In addition, this method protects the soil from potential wind erosion and helps satisfy the farmers' requirements for barley, fodder, and rangeland for the animals.

3. There is a critical need to reintroduce rangeland forages in many areas. These would ideally be forage grasses but may realistically be forage shrubs. Suitable trials need to be initiated to determine which plant species are suitable for reintroduction in the areas and the techniques required to establish the plants. Farmers need to be encouraged to protect the rangelands in dry years, whenever possible, which would include removing the animals from the areas. This will become increasingly important when new plants are being established on the land.

4. The efficiency of the cistern systems could be improved with little extra effort. Smoothing the soil in the catchment area would improve both the runoff efficiency and reduce the quantity of rain necessary to initiate runoff (threshold rainfall). These techniques may make it possible to reduce the size of the catchment areas, which would reduce the potential for sediment to be transported into the storage system. Also, the management of the stored water in the cistern could be improved by using the runoff from the early storms of winter for irrigating the trees, then refilling the storages for the summer from the late storms. Limited research on this issue showed that the probability of having a major storm in March is very high. Analysis of rainfall and runoff would give clues as to how this system could be managed for higher efficiency.

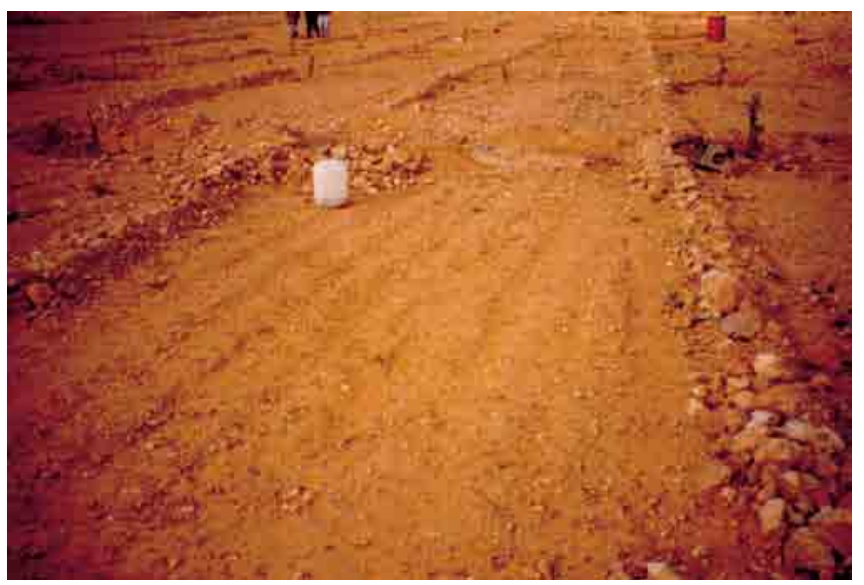

Photo 8. Microcatchment for growing trees.

5. Currently, there are many interventions for trees in shallow soil. There is a high probability that the trees will die as they get older because they require deeper soil for root development. The entire water-harvesting system must operate as a matched system with sufficient area to collect the required quantity of water, proper management of the collected water (preventing soil erosion), proper storage of the collected water, and in cropping systems, adequate soil depth for plant growth.

6. A long-term maintenance plan needs to be developed for all constructed water-harvesting systems. Farmers must be a key element in this provision. The families should be encouraged to develop ideas for how the systems could be improved.

7. Microcatchments should be used as an alternative for supporting the trees (Fig. 3). Many areas have potential for this technique.

8. Systems should be made as small scale as possible. Smallscale projects are easier to maintain, and the farmers will be more likely to perform the required maintenance.

Author is Editor of Rangelands at the Society for Range Management, Loveland, CO 80538. The author wishes to thank the International Center for Agricultural Research in the Dry Areas (ICARDA), Aleppo, Syria, for the financial support for the trip. Many thanks are extended to the personnel of the Matruh Resource Management Project for their time and effort in providing the guides and vehicles that allowed us to travel and see the various activities. A special thanks goes to Dr Theib Oweis, Irrigation and Water Management Specialist, ICARDA, Aleppo, Syria, and ICARDA's expert consultant to the project, who made the necessary arrangements and provided the excellent interface with the field personnel. This article is based on the trip report prepared by Dr Oweis and myself following the excursion into the project area. 